\title{
A case study on service quality perceptions and member retention towards Taekwondo participants in North America
}

\author{
Kim, Minkil ${ }^{\mathrm{a}}$, An, Youngseok ${ }^{\mathrm{b}}$, \& Kwon, Woong ${ }^{\mathrm{c}^{*}}$ \\ ${ }^{a}$ Associate professor, School of Hospitality, Sport, and Tourism Management, Troy University-Atlanta, USA \\ ${ }^{b}$ Grand Master, Martial Arts USA, Cypress, Texas, USA \\ ${ }^{c}$ Assistant professor, Department of Physical Education, College of Education, Jeju National University, Jeju, Korea
}

\begin{abstract}
COVID-19 continues to represent the challenge to Taekwondo (TKD) schools. TKD schools have been closed and faced with decreasing participants due to the Pandemic. The purpose of this study is to examine the extent to which service quality factors predict member intention for renewal in TKD schools. The target population evaluated for this study consisted of individuals aged at least 18 years or older who had attended a TKD schools. This study conducted for TKD members in the U.S.. A total of 159 participants were recruited via both in-person and online surveys. This study revealed that TKD members in U.S. of various demographic backgrounds had different perceptions of service quality factors that affected their attendance at TKD schools. The findings of this study will indicate the impact on the satisfaction of various TKD programs and maintenance of membership.
\end{abstract}

Key words: Physical Environment Quality, Program Activities Quality, e-Service quality, Economic Consideration Quality, Taekwondo

\section{Introduction}

Participation in physically active recreation and sports has increased tremendously in recent years due to this increased fitness and health consciousness. Along with various other activities, martial arts have become an increasingly popular recreational pursuit in Western countries. However, there has been uncertainty surrounding the effect of the virus outbreak in the sport industry. For instance, it has caused to postponement and cancellation of international sporting events,

Submitted : 15 November 2021

Revised : 12 December 2021

Accepted : 27 December 2021

Correspondence : kw73@jejunu.ac.kr including professional leagues and the 2020 Summer Olympics. The pandemic of COVID-19 has a huge impact sports events as well as significant effect on martial arts training worldwide (Helson et al., 2021; Rothan et al., 2020).

The elevated interest in martial arts has increased the magnitude of their market share. For instance, a majority of Taekwondo (TKD) schools in North America are commercial establishments. The elevated interest in TKD has expanded its market and led to the realization that TKD instruction can be a profitable business when properly managed. Besides competing with other TKD programs, a TKD school usually has to compete with other types of martial arts providers, 
such as XMA, karate, and kung fu (Kim et al., 2009). Therefore, the Business success and future growth in a highly competitive market environment depends on how well martial arts organizations understand their consumers and adapt to changes in consumer demand. It is important for the administrators of martial arts programs to identify unique variables that directly affect an individual's decision to retain a program (Kim et al., 2013; Kim \& Zhang, 2019).

In particular, no research has investigated those variables representing the attributes of service quality for private TKD schools in the U.S. To fill this void, Kim et al. (2019) identified six dimensions of attributes denoting market demand associated with TKD schools by developing the Scale of Market Demand for Taekwondo Schools (SMD-TKD) to measure key market demand dimensions. These factors were found to be representative of TKD market demand (i.e., Personal Benefits, School Operation, Instruction Quality, Program Offering, Locker Room, and Cultural Learning).

Although the current trends of growth in the TKD schools are generating new opportunities for TKD enthusiasts, rapid growth in the number of the TKD schools has resulted in a highly competitive business environment in North America (Kim et al, 2020). In addition, COVID-19 continues to represent the challenge to TKD schools. TKD schools have been closed and faced with decreasing participants due to the Pandemic.

It is assumed that satisfaction is formed based on customers' previous experience and cumulative evaluations of a TKD program, and is assumed to be a key determinant of customer retention and positive word-of-mouth (Bitner, 1990; Cronin \& Taylor, 1992). The success of a sports program depends on the extent to which it can satisfy customers with quality service. High levels of customer satisfaction would be helpful in preventing or reducing customer attrition (Muline, 2014). Membership is a major source of revenue generation for health/fitness organizations (Mullin et al.,
2014). Likewise, the ongoing operation of TKD schools primarily rely on revenues generated from its membership (Kim \& Zhang, 2019); yet, recruiting and retaining members are the most challenging for programs. Understanding specific factors that influence participation in TKD would facilitate an understanding of participants' decision-making process (Kim et al, 2009; Kim \& Zhang, 2019). No study to date has conducted a rigorous examination of service quality factors in TKD schools. The purpose of this study is to examine the extent to which service quality factors predict member intention for renewal in TKD schools.

\section{Literature Review}

\section{Taekwondo (TKD)}

Taekwondo (TKD) has rapidly grown and developed in its popularity in the world. TKD has become the world's most-practiced martial arts activity and has gained an international reputation as an Olympic sport based on the efforts of TKD enthusiasts who actively promoted the sport as a formal competitive game in the Olympics (Kim \& Zhang, 2019). The benefits of participating in TKD are widely publicized in areas of culture, spirit, mind, and body (Ko et al., 2010). To a great extent, TKD's popularity and international recognition are attributable to the concerted efforts that the Korean government has made over the years to promote this sport internationally (Kim et al, 2015; Kim et al, 2019). TKD has been the most popular discipline among various martial arts. For example, there are 80 million have participated in TKD in 210 countries and there are 206 TKD competition events in the world in 2015. TKD is increasing the number of participants, organizations, and products in the U.S. There are approximately 3 million TKD participants and more than 16,000 TKD schools in the U.S. (World Taekwondo, 2021).

There are several factors that influence the current growth of TKD: (a) change in the value of TKD 
training, (b) modernization of instructional curriculum, (c) promotional efforts made by governments of the TKD countries-of-origin, (d) increased marketing efforts in the TKD business, (e) globalization of TKD through sportification and formalization (i.e., Olympic sport), (f) the diversification of TKD products (e.g., movie and entertainment program), and (g) emergence of a new genre of TKD events (e.g., mixed martial arts competition) (Kim, Zhang, \& Ko, 2009; Kim \& Zhang, 2019).

\section{Service Quality}

The notion of service quality is a dynamic, multifaceted, and integrates a number of facets of both past and present service experiences (Biscaia et al., 2021; Rajagopal, 2014). They found that for many years in service marketing literature, numerous studies have been researched regarding the service quality. According to Bitner and Hubbert (1994), service quality has been defined as "the consumer's overall impression of the relative inferiority/superiority of the organization and its service” (p. 77). Service quality is a valuable source for organizations to gain a competitive advantage that customer would stay with an organization longer, purchase additional services, and recommend the organization to other consumers (Biscaia et al., 2017; Rajagopal, 2014; Zeithaml et al., 1996). In addition, service quality is one of the key elements that effect on customer retention/reuse and the long-term profitability of an organization. Satisfactory service quality is required to meet the needs and expectations of the customers (Stum \& Thiry, 1991).

Parasuraman et al. (1991) developed the Service Quality Scale (SERVQUAL) that takes into account the customers' perception of the relative importance of service attributes. The five key dimensions of SERVQUAL are: (a) tangibles (e.g., physical facilities, equipment, and appearance) (b) reliability (e.g., ability to perform the promised service), (c) responsiveness (e.g., willingness to help clients), (d) assurance (e.g., knowledge, competence, and courtesy of employees), and (e) empathy (e.g., caring, access, communication and understanding). They found that reliability is the most important contributor to service quality and tangibles is the least important.

\section{Service Quality in Sport}

As the sports industry becomes more globalized, the success of a sport organization depends on their ability to satisfy their customers with service quality. In addition, service quality in the recreational sport industry is assessed by the customer's overall impression of the service delivery systems, the service performance, and the whole consumption experience (Ko et al., 2010; Lam et al., 2005; Yoshida \& James, 2010). In the sport industry, both managers and researchers in the sport industry have focused on the issue of service quality due to the increasing use of these services (Lee et al., 2011).

As proposed by Brady and Cronin (2001), perceived service quality is based on customer's assessment of the fundamental three dimensions: physical environment quality, interaction quality, and outcome quality. Ko and Pastore (2005) developed conceptual model including of program quality, interaction quality, outcome quality, and physical environment. Program quality is the customer's relative perception about the program through customer experience. For example, fitness instruction and childcare service are considered primary service products in recreational sports. Interaction quality is how the service is transmitted. Outcome quality refers to an effect of the service and what the participant gains from the service. Lastly, physical environment is the tangible physical surrounding such as facility's design, ambience, and equipment. To evaluate service quality in health-fitness clubs, Lam et al. (2005) developed Service Quality Assessment Scale (SQAS) that consists of six dimensions: Staff, Program, Locker Room, Physical Facility, Workout Facility, and Child Care. Zhang (2015) also revealed the importance 
of providing quality programs and the necessity of developing diversified programs in order to achieve market penetration and expansion, as well as the importance of considering sociodemographic variables when planning marketing strategies.

\section{Theoretical Framework and Hypotheses Physical Environment Quality}

Chelladurai, Scott, and Haywood-Farmer (1987) noted that "when consumers evaluate whether to join a particular club, they may base their decision on those aspects of the club they can see, the physical evidence of the tangible facilities and goods" (p. 169). The physical environment quality dimension refers to how service delivery occurs as opposed to the natural or social environment and physical environment items is impacted to customers and employees (Bitner, 1992). The significant items included ambient conditions, space and function, signs, artifacts, symbols, and social interactions. Likewise, physical environment quality (e.g., up-to-date equipment and visually appealing facility) is considered as an important component in sport events (Ma \& Kaplanidou, 2018; Theodorakis et al., 2015).

In line with this notion, this dimension was consistent with previous studies on fitness and recreational sport facilities that identified important variables related to physical environment quality perspectives, such as ambience (Kim \& Pastore, 2005 ), program service (i.e., activity range due to facility availability, facility comfort, and safe equipment) (Howat et al., , 1996; MacIntosh \& Doherty, 2007; Yosida \& James, 2010), context (i.e., facility, location, and equipment and tools) (Chelladurai \& Chang, 2000), facility attraction, facility operations (Papadimitriou \& Karteroliotis, 2000), physical and workout facilities (Lam, et al., 2005; MacIntosh \& Doherty, 2007), and physical environment elements (i.e., ambience, design, and equipment) (Ko et al., 2011; MacIntosh \& Doherty, 2007). In martial arts perspective, Kim et al.'s (2019) study found that physical environment quality especially up-to-date equipment with a variety of functions and a visually appealing facility was important variables for TKD participants. TKD participants are often concerned about the potential for injury, so safety equipment (e.g., padded or sprung floors) is necessary for participants. In line with previous studies, the Physical Environment Quality (PEQ) dimension can impact on participants' experiences concerning participation and retention in martial arts schools (Kim et al., 2009, 2019). The previous studies leads to the first hypothesis.

H1: Perceived physical environment quality has a significant positive influence on member intention for renewal.

\section{Program Activities Quality}

Research has demonstrated that quality sport programs have the potential to foster the physical and psychosocial development of youth. Researchers noted the importance of high quality programs and developing diversified programs in order to achieve market penetration and expansion (Howat et al., 1996; Kim et al., 2009; Ko \& Pastore, 2005; MacIntosh \& Doherty, 2007).

The Program Activities Quality dimension is used to evaluate whether and how a variety of activities is offered to customers/participants. For example, Kim et al. (2013, 2019) argued that martial arts schools need to diversify their programs by integrating after-school programs, belt promotion ceremonies, tournaments, family programs, child-care services, and self-defense techniques into their program curriculum. Unlike participants in Western sports, participants in martial arts programs earn differently-colored belts that indicate their degree of proficiency. Belts are awarded on the basis of tenure, skill performance, and personal improvement. Kim et al. (2009) found that teenage American TKD participants viewed TKD training as a means of self-defense, physical exercise, and fun. In 
contrast, adult participants valued TKD training for its ability to improve their self-confidence, self-esteem, and self-discipline. Obviously, these differences should be taken into consideration in promoting/designing activity offerings of TKD programs.

Positive perceived value of the program can lead to trusting beliefs and result in intention to commit to a long-term relationship with a martial arts school, and vice versa, which would affect member satisfaction and commitment (Kim \& Zhang, 2019). The previous studies leads to the second hypothesis.

H2: Perceived program activity quality has a significant positive influence on member intention for renewal.

\section{e-Service quality}

The e-service quality is defined as a consumer's overall evaluation and judgement of the quality of the e-service delivery in the internet marketplace (Santos, 2003). It is the provision of a superior consumer experience in all aspects of the service offered through an organization's web site. Long and McMellon (2004) also found that consumers primarily make their evaluation and assessment of e-service quality based on the specific attributes of the web site interface because of the limited human interaction with the service provider in the delivery of eservices.

In particular, sport-related websites are frequently used by sports organizations as a vehicle to provide various services and additional enjoyment to consumers (Carlson \& O’Cass, 2012; Fassnacht \& Koese, 2006; Hur et al.,, 2007; Suh \& Pedersen, 2013). To extend the experience of service quality to the online sport consumption context, several studies had attempted to examine how sport fans perceive service quality provided by sport websites (Hur et al., 2011; Carlson \& O’Cass, 2012; Suh et al., 2013).

To identify e-service quality dimension, the authors Hur et al. (2011) and Suh et al. (2013) developed a specific scale to measure the quality of sport websites (Sport Web Quality, SWQ). These dimensions include the quality of information, interaction, design, reliability, and compliance. Additionally, Fassnacht and Koese (2006) and Carlson and O’Cass (2012) conceptualized sport website quality in a hierarchical framework with three primary dimensions (i.e., environment quality, delivery quality, and outcome quality). In the study, they found that the overall website-service quality customer satisfaction significantly impact on the fans' trust and loyalty to the website and it leads to customer retention (Suh et al., 2013).

The focus of e-service quality evaluations by sports consumers are made predominately via the website interface and as such, the website design is a critical issue because of its trust building role. It is argued that the positive evaluation of sports consumers' e-service quality has a positive effect on online trust formation (Carlson \& O'Cass, 2012). Although interest in e-service quality is increasing, there is no study examining e-service quality in the martial arts field. For example, Kim and Peterson (2005) the study of e-service quality has shown that consumers appear to primarily evaluate the quality of the e-service offering based on the attributes of the website interface. The previous studies leads to the third hypothesis.

H3: Perceived e-service quality has a significant positive influence on member intention for renewal.

\section{Economic Consideration Quality}

Eschenfelder and Li (2007) noted that "the expected cost and benefits decision makers in sport face are influenced by the type of economic system used to make decisions in society" (p. 26). Previous researchers have identified economic considerations as aspects of consumer perceptions of economic conditions and related variables that potentially influence their 
consumption decisions. For instance, Economic considerations usually dealt with such variables as ticket price, marketing promotion, substitute forms of entertainment, television effect, income, and competition with other sporting events (e.g., Zhang et al., 2003). Ouyan et al (2019) investigated the relationship between customer satisfaction and price sensitivity among martial arts participants. They found that the relationship between participants' satisfaction and price sensitivity was significantly different between gender and participation frequency groups.

In the setting of martial arts schools, there are likely several economic considerations, such as membership fees, payment method, discounts, refunds, membership promotions and coupons in the setting of TKD school (Kim et al., 2009, 2013). Payment system is related to pricing strategies, which is generated from the descriptive statistics revealing that a flexible payment option, reasonable membership fee and various payment methods were critically considered by program participants. The dimension of Economic Consideration Quality was shown to be most important factor to lead to member satisfaction and commitment in TKD schools
(Kim et al., 2013, 2019). They found that martial arts school administrators might consider applying family discounts, long-term membership discounts and referral discounts to retain martial arts members (Kim et al., 2019). The previous studies leads to the fourth hypothesis.

H4: Perceived economic consideration quality has a significant positive influence on member intention for renewal.

\section{Methods}

\section{Participants}

Using a convenience sampling method, data was collected from a private martial arts school located in a metropolitan city in Texas. The target population for this study was 18 years of age or older, participating in a martial arts school. A total of 159 participants were recruited via both in-person and online surveys. Participation in this study was voluntary, and all information collected was confidential. The majority of final sample consisted of male (52.2\%), Caucasian

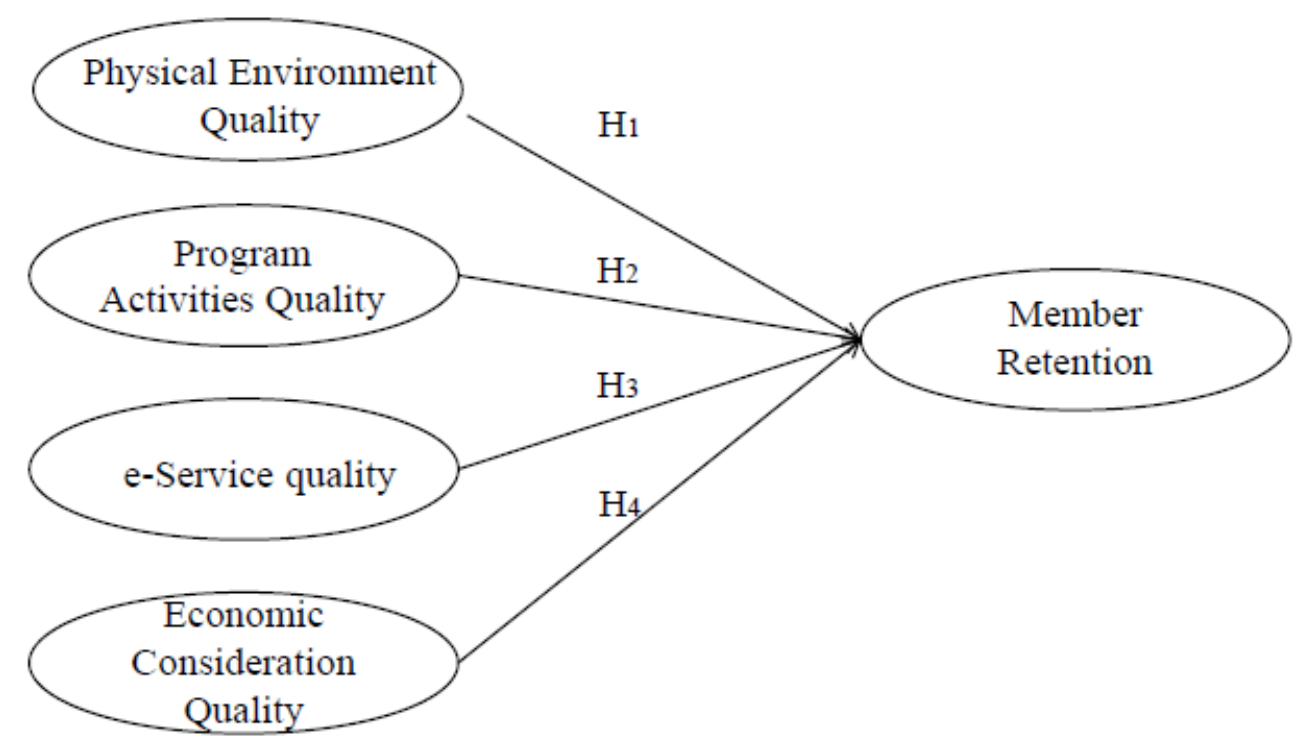

Figure 1. Hypothesized model 
(32.1\%), married (84.1\%), household income over \$100K (55.5\%), reflecting the fact that participants of TKD schools had higher levels of household income. Mean ages for the participants/parents were 9.98 and 40.49, respectively. The majority of participants indicated that they: participate three times a week (30.2\%), commute for around 10 minutes to the center (19.5\%), have been participating for around 1.57 years.

\section{Measurement and Instruments}

To measure participant's motives, perceptions, and behavioral patterns, 60 items from the SMD-TKD scale (Kim et al., 2009; 2015) were adopted and modified along with items for demographics and behavioral intentions. More specifically, the questionnaire was primarily divided into three sections: (1) demographics and behavioral, (2) satisfaction with facility/curriculum/ resources, and (3) interests in future initiatives sections. For the purpose of describing the characteristics of respondents, a sociodemographic section was included in the questionnaire that contained six variables (i.e., gender, age, ethnicity belt rank, information, and source). Multiple choice as well as fill-in-the-blank format were adopted for the sociodemographic variables. Overall scales, excluding section (1), were pretested and have received IRB approval prior to the data collection. All items were anchored by a 7-point Likert-type scale, ranging from 1 = strongly disagree to $7=$ strongly agree. Psychometric properties of the scales were tested via Cronbach's alpha and factor correlations.

\section{Sampling and Procedure}

In order to obtain responses from a large group of TKD participants while minimizing respondent errors, we took the advantage of a mixed-mode survey design, where data collection is conducted by combining on-site and online test administrations (Dillman, 2017). After receiving approval from the Institutional Review Board (IRB) involving human subjects, the researchers contacted and described the purpose of the study to the masters/instructors of TKD schools and requested permission and assistance with data collection. For on-site surveys, the researchers of the current study contacted the administrators of TKD school in a Houston area and requested for permission and assistances with the data collection. The online surveys were simultaneously conducted, which were considered as beneficial by including TKD program participants with broader backgrounds in an effort to enhance the generalizability of the research findings. Prior to the data collection, institutional review board approval was obtained.

\section{Data Analyses}

The purpose of this study is to examine the extent to which service quality factors predict member intention for renewal in TKD schools. Data screening and descriptive statistics were calculated to examine the characteristics of the data by using the SPSS 23.0 program (SPSS, 2021). A series of multiple regressions were conducted to examine the extent to which perceived service quality variables had statistically significant influence on member retention. To minimize Type I error by running a series of regressions, the alpha level was set at near zero (Hair et al., 2010).

\section{Results}

\section{Descriptive Results}

Descriptive statistics for demographic variables indicated that the majority of participants was male (52.2\%) and Caucasian (27.7\%). It is worth noting that while White male was more frequent participants, rest of participant demographics displayed much diversity as well. Refer to Table 1 for the overall report.

Descriptive statistics for participants' behavioral patterns indicated several other findings. Respondents' average weekly participant rate was around 2.7 times per week. The results further indicated that respondents 
obtained center/program information from various sources including walk-in (24.5\%), school events (18.2\%), by referral (17.6\%), internet search (15.7\%), yard signs (7.5\%), and so on.

Table 1. Descriptive Statistics

\begin{tabular}{|c|c|c|c|}
\hline Variable & Category & $\mathrm{N}$ & $\%$ \\
\hline \multirow[t]{2}{*}{ Gender } & Male & 71 & 52.2 \\
\hline & Female & 65 & 40.9 \\
\hline \multirow[t]{5}{*}{ Ethnicity } & Caucasian & 44 & 27.7 \\
\hline & Hispanic & 37 & 23.3 \\
\hline & Asian & 40 & 25.2 \\
\hline & African American & 8 & 5.0 \\
\hline & Other & 8 & 5.0 \\
\hline Variable & Frequency & $\%$ & \\
\hline Weekly participation rate & 2.68 & & \\
\hline \multicolumn{4}{|l|}{ Information sources } \\
\hline Walk-in & 39 & 24.5 & \\
\hline School events & 29 & 18.2 & \\
\hline By referral & 28 & 17.6 & \\
\hline Internet search & 25 & 15.7 & \\
\hline Yard signs & 12 & 7.5 & \\
\hline Information booth & 8 & 5.0 & \\
\hline Flyers & 7 & 4.4 & \\
\hline SNS & 2 & 1.3 & \\
\hline
\end{tabular}

Psychometric Properties of the Scales

Internal consistency of the instruments was established in that Cronbach's alpha coefficients for all four latent constructs ranged from .69 to .91. Discriminant validity among the constructs was evident in that factor correlations ranged from .29 to .84 meeting Kline's (2010) suggested criterion of less than .85 .

\section{Regression Analysis Results}

Two type of multiple regression analyses were conducted to see which service quality factors predict member intention for renewal. Essentially, Hypotheses 1-3 were supported except $\mathrm{H}_{4}$. Four independent variables including Physical Environment Quality (PEQ), Program Activities Quality (PAQ), and
Table 2. Means, Standard Deviations, and Cronbach's Alphas

\begin{tabular}{|c|c|c|c|}
\hline & $M$ & SD & $\alpha$ \\
\hline Physical Environment Quality (PEQ) & & & .69 \\
\hline Cleanness of the facility & 6.69 & .62 & \\
\hline Size of the facility & 6.13 & 1.12 & \\
\hline Location of the facility & 6.31 & 1.03 & \\
\hline Safety of overall facility (e.g., wall cushions) & 6.62 & .74 & \\
\hline Waiting space (for parents) & 5.84 & 1.34 & \\
\hline Overall equipment & 6.60 & .68 & \\
\hline Vending machine & 5.02 & 2.25 & \\
\hline More/other equipment (e.g., dummies) & 5.73 & 1.67 & \\
\hline Program Activities Quality (PAQ) & & & .76 \\
\hline Number of masters (currently 3) & 6.09 & 1.31 & \\
\hline Diversity of Taekwondo program & 6.39 & .87 & \\
\hline Pace (time management) of Taekwondo classes & 6.42 & .87 & \\
\hline Member interactions (e.g., sparing) & 6.18 & 1.08 & \\
\hline Physical training & 6.27 & 1.08 & \\
\hline Skills training & 6.31 & 1.12 & \\
\hline Mentality, etiquette, \& disciplines (life skills) & 6.48 & .86 & \\
\hline Excitement (overall fun) & 6.50 & .78 & \\
\hline Pace toward Black belt & 6.37 & .96 & \\
\hline Private lesson & 6.11 & 1.39 & \\
\hline Competition tournament & 6.23 & 1.20 & \\
\hline Quality of the program & 6.15 & 1.35 & \\
\hline Do you want the transportation program? & 2.93 & 2.00 & \\
\hline Self-defense class & 6.21 & 1.24 & \\
\hline Leadership training & 5.60 & 1.94 & \\
\hline Elite training (demonstration and tournament) & 5.45 & 1.99 & \\
\hline Holiday events & 5.16 & 2.05 & \\
\hline Weight loss programs (Cardio Kickboxing) & 5.45 & 2.10 & \\
\hline Library (parents' upgraded waiting area) & 5.43 & 2.12 & \\
\hline e-Service quality (ESQ) & & & .91 \\
\hline Instructor backgrounds & 6.31 & 1.01 & \\
\hline Information on membership fees & 5.80 & 1.33 & \\
\hline Facility amenities (pictures) & 6.21 & 1.03 & \\
\hline Access to Martial Arts USA's website & 6.38 & .93 & \\
\hline Information on registration & 6.86 & 6.83 & \\
\hline Responsiveness (answers for questions) & 6.47 & 1.02 & \\
\hline App satisfaction (MAUSA) & 6.33 & 1.17 & \\
\hline Economic Consideration Quality (ECQ) & & & .77 \\
\hline $\begin{array}{l}\text { 12-month advance payment and receive } 1 \text { month } \\
\text { discount }\end{array}$ & 5.75 & 1.70 & \\
\hline Family/sibling discount & 6.30 & 1.48 & \\
\hline Punch card for store credit (worth of \$20) & 6.05 & 1.71 & \\
\hline Referral credit (\$20 voucher) & 6.35 & 1.38 & \\
\hline Price lock program (no membership fee increase) & 6.60 & 1.12 & \\
\hline $\begin{array}{l}\text { Lifetime membership (10-year contract and } \\
\text { remaining for free) }\end{array}$ & 5.00 & 2.18 & \\
\hline Pricing of Taekwondo program & 5.83 & 1.23 & \\
\hline
\end{tabular}


Table 3. Factor Correlations

\begin{tabular}{llllll}
\hline \hline & $\# 1$ & $\# 2$ & $\# 3$ & $\# 4$ & MR \\
\hline PEQ & 1.00 & $.74^{* *}$ & $.69^{* *}$ & $.55^{* *}$ & $.47^{* *}$ \\
PAQ & & 1.00 & $.80^{* *}$ & $.49^{* *}$ & $.85^{* *}$ \\
ESQ & & & 1.00 & $.21^{*}$ & $.68^{* *}$ \\
ECQ & & & & 1.00 & $.30^{* *}$ \\
MR & & & & & 1.00 \\
\hline \hline
\end{tabular}

Note. ${ }^{*}$ and ${ }^{* *}$ indicate correlation values significant at the .05 and .01 level, respectively.

Physical Environment Quality (PEQ), Program Activities Quality (PAQ), e-Service quality (ESQ), and Economic Consideration Quality (ECQ), Member Retention (MR)

e-Service Quality (ESQ) had statistically significant in predicting member intention for renewal as a dependent variable except Economic Consideration Quality (ECQ).

The second regression analysis was conducted at the univariate level, four specific variables had statistically significant impact on member intention for renewal as follow: PEQ (i.e., location of the facility with Beta coefficients of .353) and ECQ (i.e., punch card with store credit, referral credit, and pricing of TKD program with Beta coefficients of .362, -.420, and .591, respectively). It should be noted that referral credit variable have had negative impact on the member intention for renewal while all other variables have had positive impact on the dependent variable.

\section{Discussion}

Although the current trends of growth in the TKD schools are generating new opportunities for TKD enthusiasts, rapid growth in the number of the TKD schools has resulted in a highly competitive business environment in North America (Kim \& Zhang, 2019). In addition, the Covid-19 pandemic has impacted on training worldwide and pandemic continues to represent

Table 4. Multiple Regression Analyses I

\begin{tabular}{|c|c|c|c|c|c|}
\hline \multirow[t]{2}{*}{ Independent Variables } & \multirow{2}{*}{$\begin{array}{c}\text { Standardized Coefficients } \\
\text { Beta } \\
\end{array}$} & \multirow[t]{2}{*}{$t$} & \multirow[t]{2}{*}{ Sig. } & \multicolumn{2}{|c|}{ Hypothesis Testing } \\
\hline & & & & & \\
\hline PEQ & .353 & 3.289 & .001 & $\mathrm{H}_{1}$ & Supported \\
\hline PAQ & .376 & 3.907 & .001 & $\mathrm{H}_{2}$ & Supported \\
\hline ESQ & .226 & 2.442 & .001 & $\mathrm{H}_{3}$ & Supported \\
\hline ECQ & .040 & .409 & .684 & $\mathrm{H}_{4}$ & Not Supported \\
\hline \multicolumn{6}{|l|}{ Multiple Regression Analyses II } \\
\hline \multirow[t]{2}{*}{ Independent Variables } & \multicolumn{2}{|c|}{ "Standardized Coefficients } & $t$ & Sig. & $\mathrm{R}$ square \\
\hline & \multicolumn{2}{|c|}{ Beta } & & & \\
\hline \multicolumn{3}{|l|}{$\overline{\text { PEQ }}$} & & & .34 \\
\hline \multicolumn{2}{|l|}{ Location of the facility } & .353 & 3.289 & .001 & \\
\hline \multicolumn{3}{|l|}{ PAQ } & & & .86 \\
\hline \multicolumn{3}{|l|}{ ESQ } & & & .50 \\
\hline \multicolumn{3}{|l|}{ ECQ } & & & .47 \\
\hline \multicolumn{2}{|l|}{ Punch card for store credit $(\$ 20)$} & & 3.034 & .003 & \\
\hline \multicolumn{2}{|l|}{ Referral credit (\$20 voucher) } & & -3.345 & .001 & \\
\hline \multicolumn{2}{|l|}{ Pricing of Taekwondo program } & & 7.038 & $<.001$ & \\
\hline
\end{tabular}

Note. ${ }^{*}$ indicates statistical significance at the .01 level (Bonferroni inequality adjustment applied). Dependent variable $=$ Member Intention for Renewal

Physical Environment Quality (PEQ), Program Activities Quality (PAQ), e-Service quality (ESQ), and Economic Consideration Quality (ECQ) 
the challenge to TKD schools. TKD schools have been closed and faced with decreasing participants due to the Pandemic. The purpose of this study was to examine the extent to which service quality factors predict member retention.

The overall findings of this study are generally consistent with other studies (Hallmann et al., 2012; Ko \& Pastore, 2005; Makubuya et al., 2020; Wilson \& Millar, 2021). The program quality and the physical environment were all indicative of overall service quality for recreational sport programs (Ko \& Pastore, 2005). Scholars have found largely on aspects of the physical environment as key factors influencing perceptions of service quality, including characteristics of sport facilities such as aesthetics (Gallardo et al., 2009), and availability of fitness equipment (Makubuya et al., 2020). In addition, previous study has pointed out program factors that have influenced perceptions of service quality, including the types of programs offered (Hallmann et al., 2012). Very importantly, the finding of this study revealed that benefits of TKD participation and service quality are associated with member retention.

Member intention for renewal can be a complicated process, involving an understanding of service quality-related variables. It is important for administrators of TKD school programs to identify their target market and understand those variables that directly and indirectly affect an individual's decision to retain a program. Accordingly, highly service quality for TKD program would be a significant element in an organization's efforts for maintaining long-term customer relationships (Johnson et al., 2008; Kim et al., 2019).

This study explored diverse aspects of perceived service quality towards current participants in TKD schools. In particular, participants' perceived service quality on four aspects were explored that included Physical Environment Quality, Program Activities Quality, e-Service quality, and Economic Consideration Quality. Overall measures included in the survey and their respective high ratings suggest a series of descriptors TKD school mangers/administrators can highlight in their operational management.

In perspective of physical environment quality, 'cleanness of the facility' had highest mean rating amongst physical environment variables and it indicates an important facet of the physical environment in their TKD school participation. 'Safety of overall facility' is the second highest mean. For example, prospective participants should search for schools with adequate facilities, including padded or sprung floors, full-length mirrors, and roomy practice spaces with no obstructions.

The highest mean rating of 'pace of classes' indicates importance of class flow in the actual curriculum they partake. The finding is consistent with previous studies that American TKD participants viewed TKD training as a means of self-defense, physical exercise, and fun. In addition, participants valued TKD training for its ability to enhance their self-confidence, self-esteem, and self-discipline. Obviously, these differences should be taken into consideration in promoting/designing activity offerings of TKD programs.

Among the types of e-Service quality, 'personnel responsiveness' had the highest rating, and it indicates that participants' expectation on the (speed and quality of) receptiveness when they have inquires. 'Information on registration' is the second highest mean. The finding is consistent with Carlson and O'Cass (2010) that positive e-service quality influences participants' satisfaction within the specific service context of TKD school. They concluded that if e-service is delivered and evaluated as being of sufficient quality, then satisfaction with the service delivered would result.

In regard to economic consideration, Economic Consideration Quality (ECQ) was not statistically significant in this study. However, ECQ was shown to be the most important variable. It is related to pricing strategies, which is generated from the descriptive statistics revealing that price lock and referral credit initiative have received highest interests from the respondents and this indicate what club operators can 
consider adopting, which can drive further participation in club activities. Economic Consideration Quality factor was critically considered by program participants. Thus, TKD school administrators may consider applying family discounts, long-term membership discounts, and referral discounts to retain TKD participants.

Based on multiple regression results, several key findings can be noted. First, pertaining to physical environment quality, 'facility location' was only significant predictor for member intention for renewal. This finding indicates that TKD school participants perceive these two aspects as imperative part of physical environment, which subsequently and positively influenced their school renewal intention. Three specific economic consideration quality variable turned out to be a significant predictor for member retention. This result indicates potential benefit of utilizing economic incentives (punch card for store credit, referral credit, and pricing of TKD program) to boost member retention. Interestingly, referral credit and its negative influence to member intention for renewal was a noteworthy finding.

\section{Practical Implication}

The findings of this study may suggest meaningful implications for managers in the TKD schools. The more satisfied participants are with the organization's offerings, the more likely they become to be repeat customers and encourage others to join the organization (Eggert \& Ulaga, 2002Kim \& Zhang, 2019; Maxham \& Netemeyer, 2002).

Kim et al. (2019) also recognized the importance of providing quality programs and the need to develop various programs in order to achieve market penetration and expansion by considering sociodemographic variables when planning marketing strategies. Better understanding of target segmentation facilitates market penetration and expansion of TKD schools in terms of offering a variety of customized quality programs and activities. For example, the results of this study indicate that diversity of TKD programs (i.e., excitement, fun program), self-defense, and mentality disciplines were critical reasons for participants to practice TKD. Therefore, TKD marketers may consider developing special programs that focus on these topics. Very importantly, the findings of this study revealed that program offerings based on service quality (i.e., attributes of core products) led to higher levels of participant satisfaction, which in turn led to a high level of retention.

The e-service quality factor serves as an antecedent to sports consumer attitudes towards a sporting team website (Carlson \& O'Cass, 2012; Fassnacht \& Koese, 2006; Hur et al.,, 2007; Suh \& Pedersen, 2013). Therefore, the findings suggest that TKD participant's consumers will develop a favorable predisposition to a content-based website that they perceive the website to deliver a high quality of e-service (i.e., instructor backgrounds, Mobile App, up-load facility amenities. The website quality dimensions is essential when developing and maintaining its own TKD school website. Therefore, it is essential for TKD schools to ensure the quality of the website in terms of information, personalization, system, fulfilment, design and interaction.

During the pandemic of COVID-19, the TKD School can post a recording live training section via school's website, so participants who need training on their technique may learn and progress better in an in-person environment in Covid-19 situation. In addition, TKD schools can set up a TV station in their school and using virtual classroom Software programs such as Zoom, Microsoft Teams, and other apps to teach live classes through online. It is also important that TKD schools are familiar with what COVID-19 protocols (i. e., social distancing, wearing masks, and offering small class sizes) are to keep participants safe.

It is encouraged that TKD should organize its global network structure for managing sub groups effectively and efficiently and a systematic network with other 
TKD school would help to strategize for achievement of expansion and diversification. Most importantly, the school should conduct research about understanding youth/adult TKD participants' needs and wants through more systematic research. Martial arts administrators can use the results for marketing purposes. Emphasizing the benefits experienced by participants can attract new member and member retention. The study revealed important implications for practitioners involved in TKD school and post-secondary administration. The results provide evidence that TKD training provides significant benefits to participants and contributes to retention.

\section{Limitations and Future Study}

There are several limitations of the study, which provide opportunities for future research. Frist, data was collected at a single club and, so, the results may reflect unique factors, values, and characteristics of that particular institution. As such, future research should investigate participant benefits, service quality, program satisfaction, and student retention across multiple TKD schools to allow for generalizability of the study. Second, the unique characteristics of various types of TKD members should be studied. In future research, it is necessary to review individual characteristic variables such as age, gender, ethnicity, and belt as moderator variables in order to better understand individual members. An individual's demographic characteristics influence a participant's propensity to perceive the dimension of experience. In future research, it is necessary to examine whether there are differences in experience variables according to the characteristics of individual members. Third, the sociodemographic of the respondents are not included in the statistical analysis. These factors may also affect Physical Environment Quality, Program Activities Quality, e-Service quality, and Economic Consideration Quality. This future study will be facilitated a better understanding of TKD participants. At last, a small sample size can make it difficult to determine whether a particular outcome is a true findings and can lead to type II errors in some cases. Therefore, so it is ideal for future studies to record maximum responses. In turn, future research might adopt a qualitative approach to delve into the nuances of participant benefits and perceptions of service quality or might adopt a longitudinal approach to analyze whether perceptions change throughout the training period in order to better understand individual members.

\section{References}

Biscaia, R., Yoshida, M., \& Kim, Y. (2021). Service quality and its effects on consumer outcomes: a meta-analytic review in spectator sport. European Sport Management Quarterly, 1-25.

Bitner, M. J. (1992). Servicescapes: The impact of physical surroundings on customers and employees. Journal of marketing, 56(2), 57-71.

Bitner, M.J. and Hubbert, A.R. (1994). Encounter satisfaction versus overall satisfaction versus quality: the customer's voice. in Rust, R.T. and Oliver, R.L. (Eds) Service Quality: New Directions in Theory and Practice. Sage. Thousand Oaks. CA. p. 72-94.

Brady, M. K., \& Cronin, J. J. (2001). Some new thoughts on conceptualizing perceived service quality: A hierarchical approach. Journal of Marketing, 65(3), 34-49.

Carlson, J., \& O'Cass, A. (2010). Exploring the relationships between e-service quality, satisfaction, attitudes and behaviours in content-driven e-service web sites. Journal of services marketing.

Chelladurai, P., Scott, F., \& Haywood-Farmer, J. (1987). Dimensions of fitness services: Development of a model. Journal of Sport Management, 1(2), 159-172.

Dillman, D. A. (2017). The promise and challenge of pushing respondents to the web in mixed-mode surveys. Survey Methodology, 43(1), 3-31. 
Ellahi, A., \& Bokhari, R. H. (2013). Key quality factors affecting users' perception of social networking websites. Journal of Retailing and Consumer Services, 20(1), 120-129

Eggert, A., \& Ulaga, W. (2002). Customer perceived value: a substitute for satisfaction in business markets? Journal of Business \& Industrial Marketing, 17(2-3), 107-118.

Eschenfelder, M., \& Li, M. (2007). Economics of sport: Fitness Information Technology.

Fassnacht, M., \& Koese, I. (2006). Quality of electronic services: Conceptualizing and testing a hierarchical model. Journal of Service Research, 9(1), 19-37.

Gallardo, L., Burillo, P., Garcia-Tascon, M., \& Salinero, J. J. (2009). The ranking of the regions with regard to their sport facilities to improve their facility planning in sport: The case of Spain. Social Indicators Research, 94, 297-317.

Hair, J. F., Black, W. C., Babin, B. J., \& Anderson, R. E. (2010). Multivariate data analysis (7th ed.): Pearson. New Jersey.

Howat, G., Absher, J., Crilley, G., \& Milne, I. (1996). Measuring customer service quality in sports and leisure centres. Managing Leisure, 1(2), 77-89.

Helsen, K., Derom, I., Corthouts, J., Bosscher, V. D., Willem, A., \& Scheerder, J. (2021). Participatory sport events in times of COVID-19: analysing the (virtual) sport behaviour of event participants. European Sport Management Quarterly, 1-20.

Hur, Y., Ko, Y. J., \& Valacich, J. (2007). Motivation and concerns for online sport consumption. Journal of Sport Management, 21(4), 521-539.

Hur, Y., Ko, Y. J., \& Valacich, J. (2011). A structural model of the relationships between sport website quality, e-satisfaction, and e-loyalty. Journal of Sport Management, 25(5), 458-473.

Johnson, M., Sivadas, E., \& Garbarino, E. (2008). Customer satisfaction, perceived risk and affective commitment: an investigation of directions of influence. Journal of Services Marketing, 22(5), 353-362.
Kim, M. K., \& Zhang, J. J. (2015). Promoting an Asian sport to the world: the case of Taekwondo. In Emerging trends and innovation in sports marketing and management in Asia (pp. 192-204). IGI Global.

Kim, M., \& Zhang, J. (2019). Structural relationship between market demand and member commitment associated with the marketing of martial arts programs. International Journal of Sports Marketing \& Sponsorship, 20(3), 516-537.

Kim, M. K., Zhang, J. J., Jackson, E. N., Connaughton, D. P., \& Kim, M. (2013). Modification and Revision of the Scale of Market Demand for Taekwondo Schools. Measurement in Physical Education and Exercise Science, 17(3), 187-207.

Kim, M. K., Zhang, J. J., \& Ko, Y. J. (2009). Dimensions of market demand associated with Taekwondo schools in North America: Development of a scale. Sport Management Review, 12(3), 149-166.

Kim, Y., \& Peterson, R. A. (2017). A Meta-analysis of Online Trust Relationships in E-commerce. Journal of interactive marketing, 38, 44-54.

Kline, R.B. (2010). Principles and practice of structural equation modeling. New York, NY: The Guilford Press.

Ko, J., Kim, Y., K., Kim, K. M., \& Lee, H. J. (2010). The role of involvement and identification on event quality perceptions and satisfaction: A case of US Taekwondo Open. Asia Pacific Journal of Marketing and Logistics, 22(1), 25-39.

Ko, Y. J., \& Pastore, D. L. (2005). A hierarchical model of service quality for the recreational sport industry. Sport Marketing Quarterly, 14(2), 84-97.

Ko, Y. J., Zhang, J., Catani, K., \& Pastore, D. (2011). Assessment of event quality in major spectator sports. Managing Service Quality, 21, 304-332.

Lam, E. T. C., Zhang, J. J., \& Jensen, B. E. (2005). Service Quality Assessment Scale (SQAS): An Instrument for Evaluating Service Quality of Health-Fitness Clubs. Measurement in Physical Education \& Exercise Science, 9(2), 79-111. 
Long, M. \& McMellon, C. (2004). Exploring the determinants of retail service quality on the internet. Journal of Services Marketing, 18(1), 78-90.

Ma, S. C., \& Kaplanidou, K. (2018). Effects of event service quality on the quality of life and behavioral intentions of recreational runners. Leisure Sciences, 1-21. MacIntosh, E., \& Doherty, A. (2007). Reframing the service environment in the fitness industry. Managing Leisure, 12(4), 273-289.

Maxham, J., \& Netemeyer, R. (2002). A longitudinal study of complaining customers' evaluations of multiple service failures and recovery efforts. The Journal of Marketing, 57-71.

McDougall, G., \& Levesque, T. (2000). Customer satisfaction with services: putting perceived value into the equation. Journal of Services Marketing, 14(5), 392-410.

Michael, D.C., Christopher, G., Tzu-Hui, K., \& Michelle, C. (2008). An empirical analysis of customer satisfaction in international air Travel. Innovative Marketing, 4(2), 49-62.

Makubuya, T., Kell, Y., Maro, C., \& Wang, Z. (2020). Campus wellness facility, student contentment and health. Recreational Sports Journal, 44(1), 60-66.

Mullin, B. J., Hardy, S., \& Sutton, W. (2014). Sport marketing 4th edition. Human Kinetics.

Ouyang, L., Hungenberg, E., \& Gray, D. (2019). Does a satisfied customer care about price? The link between customer satisfaction and price sensitivity in the commercial martial arts industry. Journal of Global Sport Management, 4(3), 291-311.

Oyewole, P. (2001). Consumer's socio-demographic characteristics and satisfaction with services in the airline industry. Services Marketing Quarterly, 23(2), 61-80.

Papadimitriou, D., \& Karteroliotis, K. (2000). The service quality expectations in private sport and fitness centers: A re-examination of the factor structure. Sport Marketing Quarterly, 9(3), 157-164.
Parasuraman, A., Zeithaml, V. A., \& Berry, L. L. (1991). Refinement and reassessment of the SERVQUAL scale. Journal of Retailing, 67(4), 420-450.

Rajagopal, A. (2017). Research continuum on consumer education and brand knowledge: A critical analysis. Journal of Transnational Management, 22(4), 235-259.

Rothan, H. A., \& Byrareddy, S. N. (2020). The epidemiology and pathogenesis of coronavirus disease (COVID-19) outbreak. Journal of Autoimmunity, 109, 102433. doi:10.1016/j.jaut.2020. 102433 PMID:32113704

Santos, J. (2003). E-service quality: a model of virtual service quality dimensions. Managing Service Quality, 13(3), 233-246.

Sharma, B., \& Gursoy, D. (2015). An examination of changes in residents' perceptions of tourism impacts over time: The impact of residents' socio-demographic characteristics. Asia Pacific Journal of Tourism Research, 20(12), 1332-1352.

Suh, Y. I., Ahn, T. \& Petersen, P. M. (2013). Examining the effects of team identification, e-service quality (e-SQ) and satisfaction on intention to revisit sport websites. International Journal of Sport Marketing and Sponsorship, 14(4), 261-278.

Stum, D. L., \& Thiry, A. (1991). Building customer loyalty. Training and Development Journal, 45(4), 34-36.

Theodorakis, N. D., Kaplanidou, K., \& Karabaxoglou, I. (2015). Effect of event service quality and satisfaction on happiness among runners of a recurring sport event. Leisure Sciences: An Interdisciplinary Journal, 37(1), 87-107.

Wilson, K. E., \& Millar, P. (2021). Intramural sport participation: An examination of participant benefits, service quality, program satisfaction, and student retention. Recreational Sports Journal, 45(2), 149-160.

World Taekwondo (2021). Vision, Mission, Strategy. http://www.worldtaekwondo.org/about-wt/about.html

Yoshida, M., \& James, J. D. (2010). Customer 
satisfaction with game and service experiences: Antecedents and consequences. Journal of sport management, 24(3), 338-361.

Zhang, J. J. (2015). What to study? That is a question: A conscious thought analysis. Journal of Sport Management, 29, 1-10.

Zhang, J. J., Lam, E. T. C., \& Connaughton, D. P. (2003).
General market demand variables associated with professional sport consumption. International Journal of Sports Marketing \& Sponsorship, 5(1), 33-55.

Zeithaml, V. A., Berry, L. L., \& Parasuraman, A. (1996). The Behavioral Consequences of Service Quality. Journal of Marketing, 60(2), 31-46. 